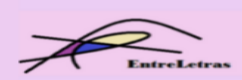

REVISTA ENTRELETRAS (ARAGUAÍNA), V. 12, N. 3, SET./DEZ. 2021 (ISSN 2179-3948 - ONLINE)

\title{
RESSIGNIFICAÇÕES DO PASSADO PARANAENSE EM TERRA VERMELHA \\ ([1998] 2013), DE DOMINGOS PELLEGRINI: \\ DA HISTÓRIA DA TERRA À HISTÓRIA DO HOMEM
}

\author{
REMEANING THE PAST OF PARANÁ IN TERRA VERMELHA (1998], 2013), BY \\ DOMINGOS PELLEGRINI: \\ FROM THE HISTORY OF THE LAND TO THE HISTORY OF THE MAN
}

DOI 10.20873/uft2179-3948.2021v12n3p301-318

\author{
Ana Maria Klock ${ }^{1}$ \\ Thiana Nunes Cella ${ }^{2}$
}

\begin{abstract}
Resumo: Este artigo analisa o romance histórico contemporâneo de mediação Terra Vermelha ([1998], 2013), de Domingos Pellegrini, em contraste com outras narrativas paranaenses Quatro Gerações (2018), de Ivo Pegoraro, e O trovador (2014), de Rodrigo Garcia Lopes com o objetivo de evidenciar como a arte literária é capaz de realizar uma releitura crítica sobre a historiografia tradicional, neste caso, sobre o processo de povoamento do norte do Paraná, mais especificamente, de Londrina. Em atenção aos referentes históricos, ancorados na abordagem de Nascimento (2009) e Mendonça (2015), bem como nos pressupostos teóricos de Mata Induráin (1995) e Fleck (2017), buscamos destacar como as narrativas híbridas de história e ficção reatualizam e problematizam o passado perpetuado pela história hegemônica, convidando à reflexão crítica, revisionista e descolonizadora do passado paranaense.
\end{abstract}

Palavras-chave: História paranaense; Londrina; Romance histórico contemporâneo de mediação;

Abstract: In this article we analyze the contemporary historical novel of mediation Terra Vermelha ([1998], 2013), by Domingos Pellegrini, in contrast with other narratives of Paraná Quatro Gerações (2018), by Ivo Pegoraro, and O trovador (2014), by Rodrigo Garcia Lopes with the purpose of evidencing how the literary art is able to perform a critical rereading on traditional historiography, in particular, on the process of settlement of the north of Paraná, more specifically, the city of Londrina. In attention to the historical references, anchored in Nascimento's (2009) and Mendonça's (2015) approach, as well as in the theoretical assumptions of Mata Induráin (1995) and Fleck (2017), we point out how the hybrid narratives of History and Fiction re-update and problematize the past perpetuated by hegemonic History, inviting to a critical, revisioinst and decolonizing reflection on the past of Paraná.

Keywords: Paraná History; Londrina; Contemporary historical novel of mediation.

\section{Introdução}

\footnotetext{
${ }^{1}$ Doutora em Letras pela Universidade Estadual do Oeste do Paraná (UNIOESTE); docente na Rede estadual de ensino do Paraná. E-mail: anamariaklock@ hotmail.com. Orcid: https://orcid.org/0000-0001-9925-3857.

${ }^{2}$ Doutoranda em Letras pela Universidade Estadual do Oeste do Paraná (UNIOESTE); docente no Instituto Federal do Paraná (IFPR), campus Coronel Vivida. E-mail: thianacella@ gmail.com. Orcid: https://orcid.org/0000-00016192-0669.
} 


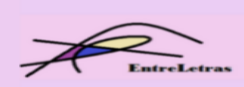

REVISTA ENTRELETRAS (ARAGUAÍNA), V. 12, N. 3, SET./DEZ. 2021 (ISSN 2179-3948 - ONLINE)

Os movimentos migratórios e os processos de instalação de cidades no Paraná são substratos temáticos para diversas narrativas híbridas de história e ficção paranaenses. Essas narrativas não apenas enriquecem o imaginário social, como também apresentam perspectivas não convencionais sobre a historiografia paranaense. Dentre as produções paranaenses contemporâneas sobre essa temática, destacamos Um amor anarquista (2005), de Miguel Sanches Neto; Quatro Gerações (2018), de Ivo Pegoraro; Retrato no entardecer de agosto (2016), de Luis Manfredini; O trovador (2014), de Rodrigo Garcia Lopes; Terra Vermelha (1998), de Domingos Pellegrini, dentre outros exemplares que reelaboram - também - outros enfoques do passado paranaense.

Neste artigo, debruçamo-nos sobre o romance histórico contemporâneo de mediação Terra Vermelha, do paranaense Domingos Pellegrini, publicado pela primeira vez em 1998, e reeditado por quatro vezes, das quais utilizamos a última: a edição de 2013 da Editora Leya, data com a qual passamos a referenciá-lo neste artigo.

Pellegrini é jornalista e escritor londrinense, autor de romances, contos, crônicas e poesias. Além de Terra vermelha, escreveu também outros dois títulos de extração histórica: Questão de honra, romance intertextual com A retirada da laguna do Visconde de Taunay, publicado em 1996; e Herança de Maria, publicado em 2012.

Em Terra vermelha (2013), revisitamos o passado de Londrina, sua instalação, povoamento e desenvolvimento até os anos finais da década de 1980. Em seu universo diegético, acessamos diversos episódios históricos regionais e nacionais, conjunturas políticas e discussões sociais, dentre as quais também focalizamos aspectos do povoamento, e suas relações com os trânsitos migratórios.

Nesse ínterim, por meio de características que o aproximam da modalidade romance histórico contemporâneo de mediação (FLECK, 2017), a narrativa realiza um exame crítico do passado paranaense e matiza elementos da historiografia tradicional, configurando-se como um recurso à problematização da história oficial e uma via ao processo de descolonização epistêmica e social.

Antes de adentrarmo-nos à análise, salientamos que este artigo é parte integrante de pesquisa doutoral desenvolvida no âmbito do grupo de pesquisa "Ressignificações do passado na América: processos de leitura, escrita e tradução de gêneros híbridos de história e ficção vias para a descolonização" CNPq/UNIOESTE; e investiga a produção de narrativas híbridas de história e ficção paranaenses em sua diacronia, traçando uma trajetória desde seus primeiros 


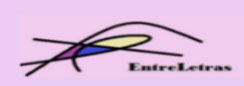

REVISTA ENTRELETRAS (ARAGUAÍNA), V. 12, N. 3, SET./DEZ. 2021 (ISSN 2179-3948 - ONLINE)

exemplares até os mais recentes, razão pela qual, estabelecemos diálogos com outras narrativas também paranaenses.

\section{A Londrina revisitada em Terra Vermelha: história da terra, história do homem}

Em Terra Vermelha (2013), conhecemos partes do processo de instalação e povoamento da cidade de Londrina, no norte do Paraná, e acompanhamos seu desenvolvimento até a década de 1980. Para tanto, somos apresentados à trajetória de Dona Sebastiana e do Sr. José Pellerini, este último, acamado em um leito de hospital. Sua história é rememorada por um neto, que conta as peripécias do avô durante sete dias e sete noites. Nesse intervalo, flutuamos por duas linhas narrativas: o presente da narrativa, restrito ao espaço do hospital e aos eventos ocorridos nesses sete dias, em que o neto conta as histórias do avô; e os episódios pretéritos rememorados por José.

Na narrativa, seguindo o estilo de composição do autor, as personagens protagônicas são inteiramente ficcionais, porém inspiradas em sua própria família: no avô paterno - também chamado José -, na avó materna - que se chama Sebastiana - e na própria mãe, que tinha uma hospedaria. De acordo com Ribeiro $(2017, \text { p. } 53)^{3}$, a narrativa carrega traços da história, da memória e da autobiografia do autor, sendo as personagens, portanto, “[...] personagens de ficção inspiradas na vida real e pertencentes ao imaginário da família Pellegrini/Pellerini”.

Essa recriação ficcional do cenário histórico, repassando conjunturas e estruturas da história local e nacional e pelas quais as personagens transitam, marca o intento de construção da verossimilhança, concebido por Fleck (2017) como uma das especificidades do romance histórico de mediação. Conforme nossa leitura, essa escolha composicional dá-se sob a prerrogativa de fornecer aos eventos históricos recuperados pela ficção um tom de autenticidade, o que contribui por firmar a ilusão de que se está diante de uma reprodução autêntica dos acontecimentos.

\footnotetext{
${ }^{3}$ Alessandra Pilati Ribero, em dissertação defendida em 2017, apresenta uma abordagem do romance a partir de conceitos relacionados à memória - coletiva e histórica - e à autobiografia: "As relações entre a ficção histórica, memória e autobiografia na obra Terra Vermelha de Domingos Pellegrini”. Neste, a autora apresenta informações sobre a vida e a obra de Pellegrini, bem como suas relações com a narrativa analisada. Ao divergirmos de sua leitura ao apresentar a obra como uma ficção histórica relacionada à metaficção historiográfica, como já mencionamos, optamos pela taxonomia narrativa híbrida de história e ficção, e classificamos a narrativa como romance histórico contemporâneo de mediação. Apesar dessa divergência formal, seu trabalho apresenta profícuo material analítico sobre a temática a que se propõe. Para maiores informações, recomendamos: RIBEIRO, Alessandra Pilati. As relações entre ficção histórica, memória e autobiografia na obra Terra vermelha de Domingos Pellegrini. 2017. 93 f. Dissertação (Mestrado em Teoria Literária) - Centro Universitário Campos de Andrade UNIANDRADE. Curitiba, 2017.
} 


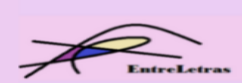

REVISTA ENTRELETRAS (ARAGUAÍNA), V. 12, N. 3, SET./DEZ. 2021 (ISSN 2179-3948 - ONLINE)

Para Nascimento (2009), Pellegrini, com Terra Vermelha, articula não só a construção ficcional do norte do Paraná na literatura nacional, como também apresenta um romance de fundação do norte do estado:

[...] imprime a marca do novo norte do Paraná na rota da literatura brasileira, como também equivale, nos nossos parâmetros, à função desempenhada por $O$ tempo $e o$ vento para o território gaúcho, ou seja, uma literatura de fundação. A saga de José Pellerini e de Sebastiana, provenientes das plantações de cana-de-açúcar do interior paulista, em direção à terra das promessas, repassa o drama de milhares de imigrantes oriundos dos vários cantos do Brasil e do mundo no rastro do ouro verde. (NASCIMENTO, 2009, 141).

Assim, o universo diegético da obra reelabora o passado londrinense ao mesmo tempo em que apresenta imagens da formação socioespacial, do processo colonizador e das migrações, reatualizando o imaginário social de determinados tempo e espaço.

De acordo com Mendonça (2015), no Paraná do século XIX e início do XX, o processo de colonização e imigração são amalgamados, pois são protagonizados por imigrantes que se estabeleceram como pequenos proprietários, atuando, portanto, como colonizadores. Desta maneira, imigração e colonização, na história do Paraná, passaram a constituir uma relação de sinonímia. Devido às necessidades basilares de ocupação do território geográfico e da produção de alimentos, houve a formação de núcleos coloniais, de modo que, oficialmente, esse processo é desdobramento dos anos coloniais:

[...] a compreensão de que a imigração na província e posteriormente no estado do Paraná esteve voltada para o povoamento e a produção agrícola de gêneros alimentícios decorre de uma abordagem que enfatiza as continuidades entre a história da imigração na região e os princípios firmados inicialmente para promoção da imigração na América portuguesa e no Brasil recém-independente. (MENDONÇA, 2015, p. 207).

No universo diegético de Terra Vermelha (2013), as conjunturas exploradas no âmbito da família Pellerini dialogam com aspectos históricos oficiais à época, tal como o papel britânico no incentivo à vinda de imigrantes, bem como a construção da Ferrovia São PauloParaná, e a consequente necessidade de mão de obra e expansão da população local. Esses fatores convergem às contingências históricas mais amplas vividas no Brasil da época, especialmente, no esforço de promover a ocupação interiorana do território:

Como no resto do país, o incentivo à imigração foi necessário, visto que era imperativo ocupar espaços vazios existentes no território do Estado, resolvendo, também, as questões relacionadas à falta de mão de obra crescente. A política do incentivo era impulsionada por propagandas que enfatizavam o Brasil como um paraíso propício à 


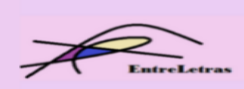

REVISTA ENTRELETRAS (ARAGUAÍNA), V. 12, N. 3, SET./DEZ. 2021 (ISSN 2179-3948 - ONLINE)

formação de fortunas, uma terra de oportunidades e de sossego, um verdadeiro paraíso no novo mundo, distante do caos que havia se tornado a Europa. (PRIORI et al, 2012, p. 35-6).

O processo de povoamento da "Nova Londres" data de 1930 e envolve um grande projeto inglês, realizado pela Paraná Plantations Limited, maior acionista da Companhia de Terras Norte do Paraná. O projeto consistiu, em linha gerais, na compra das terras pela Companhia, que construía a ferrovia e revendia as terras aos colonizadores, imigrantes e migrantes brasileiros atraídos pela promessa de terras férteis - ideais para o cultivo do café, o ouro verde - e condições facilitadas na compra dos terrenos. O processo é assim retratado na composição diegética:

\footnotetext{
Ele sentou no primeiro banco, George levava uma turma de colonos e sentou do lado, foi falando da Companhia: o plano era uma cidade a cada quinze quilômetros, como contas de um colar cujo fio seria a ferrovia. Mas a maior parte das pessoas moraria no campo, em sítios de no máximo trinta hectares; e todos os lotes à venda eram em glebas de mata virgem, compridos como espinhas de peixe embicando no riacho para que todos tivessem água corrente na baixada, e na outra ponta, no alto do espigão, uma estrada; a Companhia vivia abrindo estradas nas glebas. Seriam uma dezena de cidades, milhares de sítios, uma beleza de colonização, o olhos-azuis já via tudo pronto e acabado. (PELLEGRINI, 2013, p. 119).
}

Em Terra vermelha (2013), é a partir dessa ótica que as terras são divulgadas pelos ingleses. A mesma temática também é explorada por outra narrativa híbrida de história e ficção paranaense: O trovador, de Rodrigo Garcia Lopes, publicada em 2014.

Exemplar de romance histórico contemporâneo de mediação, $O$ trovador explora a Londrina de 1936 ao mesmo tempo em que tece uma intrincada investigação criminal. Nessa, estabelece paralelos entre um poema trovadoresco enviado à Inglaterra, o desaparecimento de um casal de funcionários da Paraná Plantations Limited, junto a uma trama envolvendo desvio de recursos da companhia, um grupo extremista de apoio ao nazismo alemão e a desistência do então Rei do Reino Unido e dos Domínios Britânicos e Imperador da Índia, Eduardo VIII - que se tornaria Duque de Windsor.

Em ambos os romances, os primeiros anos da cidade de Londrina são apresentados como um período de recepção de pessoas e famílias ávidas por conhecer e enriquecer na nova terra, retratada como um centro de efervescência cultural, em que todas as etnias e nacionalidades eram bem-vindas.

O discurso laudatório à terra fértil da chamada "filha de Londres" também é uma constante nas narrativas: "[...] no outro lado do rio as árvores seriam ainda maiores, a terra seria vermelha mesmo, rossa como diziam os italianos, macia e funda: - A melhor terra do mundo." 


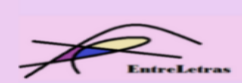

REVISTA ENTRELETRAS (ARAGUAÍNA), V. 12, N. 3, SET./DEZ. 2021 (ISSN 2179-3948 - ONLINE)

(PELLEGRINI, 2013, p. 77). Essa propaganda e a valorização da terra vermelha atraíam a população que buscava diferentes oportunidades no "Novo Mundo", especialmente devido ao incentivo ao cultivo de café e o suposto acesso facilitado à posse de seus terrenos:

\begin{abstract}
Em dez anos, a "cidade-jardim" planejada na City de Londres havia crescido bem mais que os 5 mil habitantes imaginados a princípio, e tudo indicava uma rápida evolução. Com a propaganda agressiva dos últimos anos, a venda de lotes havia aumentado em progressão geométrica. Havia grande expectativa em torno do café. Por outro lado, a Paraná Plantations já colhia os frutos de seu empreendimento, o que significava mais dinheiro circulando na "nova Canaã". A Terra da promissão. (LOPES, 2014, p. 57).
\end{abstract}

Apesar do discurso laudatório à fertilidade e receptividade das terras, as duas narrativas convergem quanto à representação crítica do papel da companhia Paraná Plantations Limited no processo de colonização:

\footnotetext{
- Os ingleses quiseram plantar aqui uma colonização exemplo para o mundo, como papaguearam, mas implantaram foi uma semiescravidão chamada colonato!

O povo de Londrina e do Norte do Paraná, dizia alto de dedo esticado, o povo tinha sido enganado; primeiro pelos ingleses:

- A Companhia comprou do Paraná mais de meio milhão de hectares a preço de banana; daí abriram as primeiras cidades e glebas, e a terra valorizou tanto que venderam por uma fortuna e voltaram pra Inglaterra! Foi o golpe da colonização! (PELLEGRINI, 2013, p. 251).
}

A postura revoltada da personagem Mané Felinto é indicativa das dificuldades geradas pelo processo de povoamento da cidade, especialmente relacionadas à desigualdade social. De acordo com Mendonça (2015), apesar de os fluxos migratórios estarem estreitamente relacionados à agricultura e à produção de alimentos, o processo de povoamento paranaense ocorre em conformidade à coexistência de duas faces das políticas imigratórias nacionais:

[...] uma delas esteve restrita às regiões meridionais e outra à área da grande produção cafeeira; uma, teria gerado uma sociedade de pequenos proprietários; outra, voltada aos interesses dos latifundiários, proletarizou os imigrantes, transformados em substitutos dos escravos nas lides da grande lavoura de exportação. (MENDONÇA, 2015, p. 209).

Em Terra Vermelha (2013), José Pellerini e Dona Sebastiana - ou dona/vó Tiana, como era comumente chamada -, iniciam sua história em uma competição de corte de cana em Capivari, uma cidade dividida pela rivalidade com uma de suas vilas, chamada Rafard. De Capivari, os dois vão para Londrina, passando alguns anos em Ourinhos e Cornélio Procópio, até se instalarem definitivamente na terra vermelha. Dona Tiana cozinhava e abria pensão por onde passava, fazia dinheiro e cuidava dos filhos; José, após muitas tentativas malfadadas de 


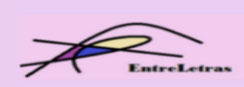

REVISTA ENTRELETRAS (ARAGUAÍNA), V. 12, N. 3, SET./DEZ. 2021 (ISSN 2179-3948 - ONLINE)

trabalho - de tropeiro e corredor a dono de bar e farmácia -, estabiliza-se na profissão de olheiro, como eram chamados os corretores de venda de terras.

Em suas trajetórias, ambos ganham reconhecimento por seus trabalhos pioneiros e benfeitores na cidade, Tiana abre a Hospedaria Pioneira, José realiza projetos ecológicos pela cidade, candidata-se a vereador, tornam-se uma família próspera, prestigiada pela população.

Junto à apresentação da trajetória do casal - dos anos 1920 até 1989 -, são também contemplados diferentes momentos e eventos históricos do Paraná e do Brasil, tais como a Revolução Constitucionalista de 1932, a Ditadura Militar (1964-1985), o período da Guerra Fria (1947-1991), até a queda do Muro de Berlim (1989). Esses diálogos com a história são contínuos, e apresentados de maneira informal, mesmo que por um olhar crítico, tal como ocorre no excerto a seguir:

Contou que em 32 a revolução paulista tinha isolado Londrina do mundo, quando ainda era um povoadinho chamado Patrimônio Três Bocas. O Paranapanema tinha virado a primeira trincheira paulista e nem tropeiros passavam mais, toda comida ali tinha então de sair da mata e do rio. (PELLEGRINI, 2012, p. 79).

A primeira grande revolta contra o governo Getúlio Vargas, a Revolução de 1932, foi um movimento armado que teve espaço nos estados de São Paulo, Mato Grosso do Sul e Rio Grande do Sul, de julho a outubro de 1932. Motivados pela insatisfação do governo provisório de Getúlio Vargas, os revoltosos buscavam convocar uma Assembleia Nacional Constituinte. Geograficamente, o Paraná ficava entre os estados conflitantes, motivo pelo qual muitos homens tiveram de lutar, e partes do estado ficaram isoladas.

Além dos episódios supracitados, o processo de povoamento de outros estados também é relembrado, tomando-os como exemplo do que aconteceria com o Paraná: "Em Minas e São Paulo, contou o homem, também tinha sido assim: - No começo, um mar de mata. Depois do café, um deserto." (PELLEGRINI, 2013, p. 83). Essas inserções são apresentadas de maneira crítica, sem enaltecer ou se coadunar ao processo colonizador, mas exprimindo os danos que o processo causava, tanto social como ecologicamente: “- Meu pai conta que em Minas foi a mesma coisa, derrubaram toda a mata pro café, a terra ressecou, acabou o café e ficou uma fieira de cidadezinhas, uma mais pobre que a outra" (PELLEGRINI, 2013, p. 84).

Com base no que explica a pesquisadora Sandra Marcondes (2015) sobre as atividades extrativistas, vejamos como o trecho recupera o que postula o discurso historiográfico sobre a questão: 


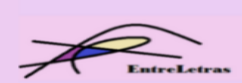

REVISTA ENTRELETRAS (ARAGUAÍNA), V. 12, N. 3, SET./DEZ. 2021 (ISSN 2179-3948 - ONLINE)

\begin{abstract}
A ocupação das terras para a plantação do café no Brasil, infelizmente, seguiu da forma "tradicional" do passado, com significativas derrubadas das matas e posterior queima da madeira. A exploração cafeeira seguiu o mesmo modelo da açucareira: grande propriedade, monocultura e trabalho escravo. [...]. Os instrumentos básicos de trabalho da lavoura cafeeira eram a enxada e a foice. O emprego do arado pelos fazendeiros do café somente iria generalizar-se por volta de 1870 nas zonas novas de São Paulo. As tarefas na lavoura desenvolviam-se da seguinte maneira: derrubava-se a mata, utilizavase parte da madeira e tocava-se fogo no resto. Não havia princípio científico algum para a escolha das matas a serem derrubadas. [...]. A derrubada começava na madrugada e os escravos reunidos começavam o trabalho da destruição. A submata e os cipós retrançados eram cortados com foices para abrir caminho aos machadeiros que vinham atrás. Depois de limpo o chão, em volta de uma árvore, o machadeiro começava a cortar a altura da cinta, ou às vezes em cima de uma plataforma. [...]. As queimadas, feitas de forma descuidada, espalhavam-se pelas fazendas vizinhas. (MARCONDES, 2005, 84$85)$.
\end{abstract}

Dessa forma, ao apresentar a crônica da vida do casal - especialmente de Seu José -, a narrativa plasma a realidade histórica à época. Algumas personagens emblemáticas reforçam as relações entre o substrato histórico e os elementos ficcionais, dos quais podemos destacar Mané Felinto - personagem de extração ficcional inspirado em Mané Jacinto, pedreiro de ideologia comunista que foi vereador em Londrina -, Lázaro Góis, seu adversário político também inspirado na personalidade factual Álvaro Godoy -, e Zé do Cano, fiel defensor do sistema capitalista (RIBEIRO, 2017).

A presença das personagens ficcionais secundárias Zé do Cano e Mané Felinto fazem com que discussões sobre comunismo e capitalismo sejam constantes, pois, apesar de amigos, são antagônicos em seus posicionamentos socioideológicos, tal como podemos ratificar no seguinte trecho: "Mané Felinto disse que o ouro era uma invenção do capitalismo, Zé do Cano disse que as moedas eram de ouro na Roma Antiga, quando ainda nem existia capitalismo. Começaram a discutir enquanto Mané Preto mostrava [...]" (PELLEGRINI, 2013, p. 162). Essas pequenas discussões são constantes em toda a diegese e colaboram nos aspectos históricos e posicionamentos questionadores do romance:

Os americanos cercando Cuba, Mané Felinto batendo no peito:

- Se invadirem a ilha, eu vou lá lutar!

Os americanos no Vietnã.

- Se eu pudesse, eu ia lá lutar!

Passeata dos Cem Mil no Rio de Janeiro.

- Eu queria estar lá!

Zé do Cano botando a mão no ombro de Mané:

- Você deveria é pagar aposentadoria, meu amigo, que você não é eterno.

- Meu dinheirinho suado não vai ajudar a sustentar esse regime. (PELLEGRINI, 2013, p. 340).

Tais inserções ocorrem também no presente da narrativa, quando José está no leito de hospital e recebe visitas. Como fica explícito no excerto a seguir, em que Manuel Felinto, que 


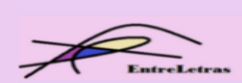

REVISTA ENTRELETRAS (ARAGUAÍNA), V. 12, N. 3, SET./DEZ. 2021 (ISSN 2179-3948 - ONLINE)

não assistia à televisão, fica sabendo por Zé do Cano sobre a queda do Muro de Berlim, em 10 de dezembro de 1989:

Pois é, Mané, ontem caiu o Muro de Berlim.

O velho comunista é antes de tudo um sertanejo arisco; não fala nada fica olhando o outro de viés.

- Não estou brincando, Mané, o Muro de Berlim caiu ontem.

- Como? - um sorrisinho de desdém - Quem derrubou? [...]

Gente dos dois lados do muro, Mané, com flores e picaretas. (PELLEGRINI, 2013, p. 198).

É comum, portanto, em Terra Vermelha (2013), o entrecruzamento temporal e temático entre a narração do passado e o presente da narrativa. Para Ribeiro (2017), ambas as linhas narrativas se articulam a tecer relações críticas com valores que se perderam no tempo:

\begin{abstract}
Um bom exemplo disso é a história da atuação do Partido Comunista no interior do Paraná nas décadas de 1940 e 1950, entremeada com a queda do Muro de Berlim em 1989, quando José se encontra no hospital rodeado pelos filhos e pelos netos. O confronto entre tempo passado e presente, portanto, funciona como denúncia de valores e ideologias já obsoletos, evidenciando o potencial crítico da produção de Pellegrini em seu diálogo com dados da memória coletiva e da história. (RIBEIRO, 2017, p. 23).
\end{abstract}

Adicionamos, ainda, que além de revisar esses valores considerados por ela obsoletos, essas estratégias composicionais reforçam a necessidade de um enfrentamento perscrutador da historiografia tradicional, bem como são metonímicos ao simbolizar como o passado e o presente confluem e alçam novas reflexões sobre o transcorrer do tempo: passado, presente, futuro. Sobre tal capacidade das narrativas híbridas de história e ficção, Mata Induráin (1991, p. 59) assevera: "Presente y pasado se hermanan en la novela histórica: por un lado, la visión del pasado se ilumina con los conocimientos del presente y, a su vez, la comprensión del pasado enriquece la del mundo actual y nos hace mirar con ojos nuevos al porvenir ${ }^{4 "}$. Nas narrativas híbridas de história e ficção, portanto, a afluência de elementos históricos junto aos ficcionais também possibilitam que recuperemos aspectos da memória histórica e da memória coletiva, reatualizando a experiência do passado no presente.

Em Terra vermelha (2013), como mostramos, ocorre a reatualização de diferentes episódios históricos, dentre eles está o período nacional vivido em Regime Militar (1964-1985). Na composição diegética, durante a ditadura militar, por mais de uma vez, Mané Felinto foi

\footnotetext{
${ }^{4}$ Nossa tradução: Presente e passado se unem no romance histórico: por um lado, a visão do passado se ilumina com o conhecimento do presente e, por sua vez, a compreensão do passado enriquece a do mundo atual e nos faz olhar com novos olhos para o futuro.
} 


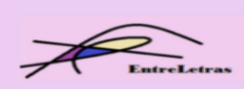

REVISTA ENTRELETRAS (ARAGUAÍNA), V. 12, N. 3, SET./DEZ. 2021 (ISSN 2179-3948 - ONLINE)

preso devido aos seus ideais e suas atividades no Partido Comunista, revisitando, assim, os períodos em que a nação esteve sob o jugo dos militares e denunciando o autoritarismo e a violência arbitrária:

- Quantas vezes o senhor apanhou da polícia, Seo Mané? - pergunta o filho mais velho.

O velho sorri com os dentes miúdos de sertanejo:

- Apanhar não apanhei muito, fui mais é torturado.

Silêncio.

- Tem muita diferença. (PELLEGRINI, 2013, p. 188)

De fato, no universo diegético, as marcas da ditadura militar são inúmeras, as quais são inseridas com tom de denúncia social, expondo as injustiças, a violência e o abuso de poder dos militares e oficiais regionais, como é exemplar do seguinte trecho, em que José e Tiana entraram em conflito com oficiais e foram agredidos arbitrariamente:

\footnotetext{
- O senhor respeite!

Respeitar o quê?! Ele explode: um bando armado caçando gente pela rua, sem mandato de juiz nem autoridade de polícia?

- Os senhores saiam daqui já!

Murro na boca, coronhada na cabeça, cara no chão. Tiana levando empurrão. Ele pulando no pescoço de um, levando murros e pontapés dos outros. Jogado em portamalas da caminhoneta, jogado num salão da prefeitura, com outros também já espancados. Oficiais do Exército bebendo café com fazendeiros armados, rindo e aplaudindo notícias no rádio, a revolução redentora vitoriosa, comunistas caçados em todo o território nacional. (PELLEGRINI, 2013, p. 324).
}

Essa postura de denúncia e crítica social que permeia toda a narrativa é basilar na modalidade do romance histórico contemporâneo de mediação, pois os mesmos " [...] ecoam as vozes silenciadas de todas as camadas sociais marginalizadas e excluídas das escritas hegemônicas do passado da América Latina cujas bases ideológicas estiveram submissas aos centros irradiadores do poder e a suas ações coercivas" (FLECK, 2017, p. 128). Do mesmo modo, o aspecto crítico de Terra Vermelha (2013) estende-se a outros períodos da historiografia nacional, como podemos verificar no excerto a seguir em que o mito colonizador é questionado:

Depois que os índios se foram, depois de trocar peixes por sal, o professor contou que eram os últimos da raça caingangue, seus antepassados tinham lutado com os portugueses e os bandeirantes e quase todos tinham morrido.

- Esses são o que restou, decerto filhos dos que não lutaram.

- Portugal descobriu o Brasil, professoire, não para matar índio.

- Mas mataram. (PELLEGRINI, 2013, p. 247). 


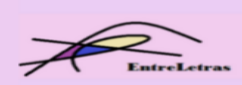

REVISTA ENTRELETRAS (ARAGUAÍNA), V. 12, N. 3, SET./DEZ. 2021 (ISSN 2179-3948 - ONLINE)

São nessas passagens em que reconhecemos o aspecto perscrutador de Terra vermelha (2013), ao não se coadunar ao discurso apologético da historiografia, não exaltando o avanço civilizatório, a supremacia do colonizador, ou de quem está no poder. Essa mudança de paradigma, portanto, é observada nas manifestações recentes do gênero híbrido de história e ficção que, conforme López Badano (2010, p. 53),

[...] puede afirmarse que la novela histórica contemporánea ha aprendido a hablar en los silencios del discurso historiográfico, a ser testigo crítico de su positivista vocación absolutizadora, de su hoy insostenible soberbia cientificista, revelando una historia que, aunque "verdadera", se vuelve más "auténtica" que la fáctica en su apertura psicológicoantropológica."

Além do olhar questionador sobre o processo de colonização nacional, a querela comunismo x capitalismo e a ditadura militar, outro aspecto bastante discutido no universo diegético é a reforma agrária, com discussões alçadas por Lázaro Góis: fazendeiro que, no universo diegético, herdou suas terras, multiplicou-as e desenvolveu grande apreço pela mata, não permitindo caçadas ou qualquer alteração em suas terras, deixando a tarefa para o irmão, mesmo depois da desapropriação do Estado: “O Estado tá mais quebrado que palavra de político, não tem dinheiro nem para consertar a cerca, então não mudou nada, continuo cuidando. Ninguém mexe lá um pau enquanto eu viver.” (PELLEGRINI, 2013, p. 353). No plano da narrativa, o protagonista também busca proteger a mata, cria um projeto de arborização, questiona a poda excessiva de árvores, compra terras para deixá-las intocadas.

A personagem protagonista, Seu José, é apresentada como um homem simples, que enfrentou grandes dificuldades antes de prosperar. Esta é uma peculiaridade cara aos romances históricos contemporâneos de mediação, os quais privilegiam “[...] visões a partir das margens, sem centrar-se nas grandes personagens da história” (FLECK, 2017, p. 110) e que, por essa razão, comungam com os ideais da Nova História ao proporem uma perspectiva da história "vista de baixo" (SHARPE, 1992).

Aqui, salientamos uma das tendências do romance histórico paranaense: a narrativa da vida de uma personalidade, principalmente, da vida de um homem. Essa característica está presente desde os primeiros exemplares, como em O drama da Fazenda Fortaleza, de David

\footnotetext{
${ }^{5}$ Nossa tradução: [...] pode afirmar-se que o romance histórico contemporâneo tem aprendido a falar nos silêncios do discurso historiográfico, a ser testemunho crítico de sua positivista vocação absolutista, de sua atual insustentável soberba cientificista, revelando uma história que, ainda que "verdadeira", torna-se mais "autêntica" que o factual em sua abertura psicológica-antropológica.
} 


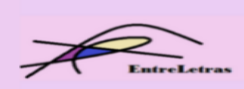

REVISTA ENTRELETRAS (ARAGUAÍNA), V. 12, N. 3, SET./DEZ. 2021 (ISSN 2179-3948 - ONLINE)

Carneiro, publicado em 1941, como em exemplares mais recentes, como é o caso de Quatro gerações, de Ivo Pegoraro, publicado em 2018.

Quatro Gerações (2019) também é um romance histórico contemporâneo de mediação, no qual a postura crítica aparece de forma bastante sutil. Sua personagem protagonista é Tôni - José Antônio Enearo -, o qual foge do Rio Grande do Sul, reside um período em Santa Catarina, onde participa da Guerra do Contestado (1912-1916), e transita até o sudoeste do Paraná, onde permanece. Na região, participa da fundação de cidades como Clevelândia, Pato Branco e Vila Marrecas - atual Francisco Beltrão. O universo diegético apresenta aspectos da história local, a busca por novos solos férteis e o consequente povoamento da região, suas implicações com a instalação da Colônia Agrícola General Osório (CANGO), a posterior fundação da Clevelândia Industrial e Territorial Ltda (CITLA) e a rebelião que culmina com a Revolta do Posseiros, em $1957 .{ }^{6}$

Assim como em Terra Vermelha (2013), Quatro Gerações (2018) acompanha a trajetória de Tôni e sua família, suas desventuras e conquistas, a partir de uma ótica periférica, incluindo a dureza da escassez de recursos, as fatalidades ocorridas pelo subdesenvolvimento local, as inúmeras querelas ocasionadas pela disputa de posses de terra.

No deslindar da narrativa, reencontramos momentos históricos conturbados, tais como o Estado Novo e a Ditadura Militar e as problemáticas sobre os processos de colonização e utilização do solo: "Foi assim que fizeram no Rio Grande do Sul, até que a fertilidade do solo se esgotou e aí vieram explorar novas terras no Paraná. E quando o solo daqui também se esgotar? Bem, aí serão outros tempos, outras histórias.” (PEGORARO, 2018, p. 262).

Além de seus aspectos historiográficos, o universo diegético acompanha o crescimento da família de Tôni, a dispersão das personagens, bem como as muitas mortes ocorridas - há muitas tragédias familiares na trama, ponto bastante característico à época ressignificada. Ao final da narrativa, junto aos filhos, o protagonista retorna à região do Contestado, rememora os tempos do conflito e de mocidade.

Estruturalmente, a narrativa é fluída, com linguagem coloquial, bastante próxima à oralidade, com uso de termos de origem italiana, conferindo leveza, agilidade e humor ao romance.

\footnotetext{
${ }^{6}$ Também conhecida como Revolta dos Colonos, foi um levante realizado por colonos e posseiros armados iniciado em 10 de outubro de 1957 como forma de repúdio aos problemas de colonização da região que se estabeleceu entre posseiros, colonos, companhias de terras grileiras e os governos federal e estadual. Em linhas gerais, a companhia vendia terras que não lhes pertencia efetivamente, estava em sub judice, após um período de conflitos com capatazes/jagunços que tentavam retomar as terras. Quando perceberam que poderiam perder suas terras, os colonos organizaram o levante e saíram vitoriosos.
} 


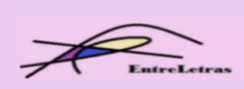

REVISTA ENTRELETRAS (ARAGUAÍNA), V. 12, N. 3, SET./DEZ. 2021 (ISSN 2179-3948 - ONLINE)

Nessas narrativas - Terra vermelha (2013) e Quatro gerações (2018) -, portanto, acessamos à história vista por uma perspectiva descentralizada, a ótica de pessoas comuns, de quem esteve fora do poder hegemônico. Essa peculiaridade, como já salientamos, é essencial para a construção do romance histórico contemporâneo de mediação, que tenciona humanizar a historiografia sem os fins desconstrucionistas das modalidades anteriores:

\begin{abstract}
Pelas lentes dessa personagem das margens, que ocupa o centro da diegese, a história é subjetivada e a "verdade" hegemônica é questionada. A personagem do romance de mediação contrasta com a das modalidades do novo romance histórico e metaficção historiográfica - que buscaram desconstruir grandes personagens históricas. Na atualidade, vemos que os autores abandonam o uso de diferentes pontos de vista para encarar o passado, criando um complexo jogo de discursos que se entrecruzam. (KLOCK, 2021, p. 183).
\end{abstract}

De fato, nessas narrativas, o aspecto crítico e questionador é inserido de forma a não impactar o narratário, mas seu teor questionador é apresentado na fluidez da narrativa, como podemos afiançar no seguinte trecho de Quatro gerações (2018), em que Tôni, ao dissertar sobre o ano de 1968, expõe as mazelas nacionais:

\footnotetext{
Quanta coisa aconteceu neste marcante 1968, de maneira positiva para Tôni, de maneira atroz para o Brasil. Aqui, bons negócios, boas surpresas; lá, broncas, provocações, perseguições, prisões, mortes, entre estudantes e polícia; divergências entre o Executivo e o Congresso Nacional, resultando na criação de mais um monstro, o AI-5 - ato inconstitucional que deu superpoderes ao presidente da República e decretou o início de uma década macabra para a história brasileira. (PEGORARO, 2018, p. 330).
}

Além da criticidade histórica subjacente ao romance histórico contemporâneo de mediação, as trajetórias de José e Tôni alicerçam-se no processo de colonização e desenvolvimento do estado do Paraná a partir de personagens protagônicas comuns, sobre as quais recai o foco narrativo - centralizado e ex-cêntrico, portanto.

À vista disso, estruturalmente, Terra vermelha (2013) comunga das características basilares da modalidade romance histórico contemporâneo de mediação - como é por nós classificado: por meio de linguagem fluída e coloquial, a narrativa apresenta uma releitura crítica e verossímil do passado, alcançada seguindo a linearidade cronológica dos eventos e possui seu foco narrativo centralizado em uma personagem protagônica que não se enquadra no rol das grandes e heroicas personalidades da história.

Como já mencionamos, a obra é conduzida por dois planos/fios narrativos: aquele do presente da narrativa, em que o neto conta a história do avô e onde desenrolam os 


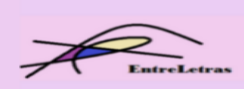

REVISTA ENTRELETRAS (ARAGUAÍNA), V. 12, N. 3, SET./DEZ. 2021 (ISSN 2179-3948 - ONLINE)

acontecimentos no hospital; e o fio narrativo pretérito, em que são relatadas as histórias de José e Tiana, junto ao desenvolvimento de Londrina.

Como já é possível averiguar nos trechos transcritos no decorrer dessa análise, em ambos os fios narrativos, um narrador extradiegético divide espaço com a fluidez dos diálogos e dos pensamentos das personagens, em uma transição contínua entre o discurso direto, o discurso indireto e o discurso indireto livre - aproximando a narrativa da oralidade - , utilizando pontuações alternadas, com ou sem parágrafos e travessões, maiúsculas ou minúsculas, como é possível verificarmos no seguinte trecho:

Então muito bem - ele falou fazendo um cigarro - já tinham dividido tudo? Porque ainda não tinham chamado para assinar os papéis no cartório? - E picava o fumo.

Ninguém respondeu, todos olhando os sapatos, acendendo cigarros, até que ele enrolou o dele, perguntou se estavam ficando surdos.

- Ou então estão pensando que estou ficando bobo. (PELLEGRINI, 2013, p. 13).

Essas estratégias narrativas fazem de Terra vermelha (2013) uma obra com alto teor de refinamento estilístico. Para Sanches Neto (2013, s.p.), o esquema narrativo traçado por Pellegrini caracteriza uma obra prima da arte romanesca, um grande épico, “[...] que concilia fluência a um domínio absoluto do papel do narrador". Ademais, identificamos nesse estilo composicional outra característica recorrente ao romance histórico contemporâneo de mediação, na qual "[...] as frases são, geralmente, curtas e elaboradas de preferência em ordem direta, e com um vocabulário mais voltado ao domínio comum que ao erudito" (FLECK, 2017, p. 111).

Sobre o papel do narrador, Benjamin (2012, p. 214) assevera que "A experiência que passa de boca em boca é a fonte a que recorreram todos os narradores. E, entre as narrativas escritas, as melhores são as que menos se distinguem das histórias orais contadas pelos inúmeros narradores anônimos”. Essas características perpassam as estratégias de Pellegrini, uma vez que verificamos as confluências de histórias, de memórias, de eventos históricos e personagens no deslindar de toda narrativa. Os sinais de oralidade, como mencionamos, são frequentemente evidenciados tanto pelas escolhas lexicais e estilísticas, como pela alusão a histórias, mitos e crenças populares:

[...] e mexendo os olhos contou a história do povo preto, que era preto como todo mundo no começo do mundo, quando pediram a Deus para ficar brancos, só para variar, e Deus então mandou todo mundo se banhar num lago, onde iam ficando todos brancos. Mas o lago foi secando com tanta gente, até que os últimos só puderam molhar as palmas das mãos e dos pés - e mostrou as palmas das mãos brancas encaroçadas de calos. Mas, continuou, Deus ficou com dó e resolveu que, em 


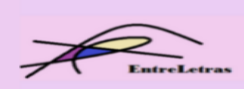

REVISTA ENTRELETRAS (ARAGUAÍNA), V. 12, N. 3, SET./DEZ. 2021 (ISSN 2179-3948 - ONLINE)

compensação, os pretos iriam ter os dentes mais brancos, cada dente uma joia. (PELLEGRINI, 2013, p. 162).

São por alusões como essa que somos colocados em contato com a oralidade e a cultura popular da época. Ainda como artifício que nos aproxima da oralidade, colaborando também no lirismo e delicadeza da narrativa, Tiana compunha versinhos sobre o dia a dia, a culinária, a vida, muitas vezes, transformando problemas de uma forma leve e poética: "Na meia-idade / só o que me espanta / é já tanta saudade” (PELLEGRINI, 2013, p. 302), traço também presente nas conversas do casal:

Tiana olhando os túmulos de pioneiros:

- A vida é pouco a pouco e também de repente, né? De repente a gente tem netos, de repente quebra um dente, de repente morre alguém, a gente olha e, de repente, tem mais vida pra trás do que pra frente.

- E o remédio é viver, não é?

- Não, o remédio é viver bem, José. (PELLEGRINI, 2013, p. 323).

A comunhão dessas particularidades aproxima nossa interpretação de Terra vermelha (2013) ao que o autor húngaro chama de “[...] lenta superposição de camadas finas e translúcidas, que representa a melhor imagem do processo pelo qual a narrativa perfeita vem à luz do dia a partir das várias camadas constituídas pelas narrações sucessivas.” (BENJAMIN, 2014, p. 223). Essas camadas, no romance em questão, são tecidas com engenhosidade e perspicácia, criticidade e sutileza.

Apesar de possuir dois fios narrativos condutores - o presente da narração, que ocorre no hospital, e as peripécias pretéritas -, Terra Vermelha (2013) mantém a linearidade sequencial dos eventos que elege recriar - fator que a distancia das modalidades críticas descontrucionistas do novo romance histórico e da metaficção historiográfica. Não há, no entanto, marcações formais de tempo ou datas, com exceção dos títulos dos capítulos. No total, a narrativa divide-se em 15 capítulos, o primeiro, intitulado "Último desejo", e na sequência 14 capítulos que marcam "Primeira noite", "Primeiro dia", "Segunda noite", "Segundo dia", e assim sucessivamente até o sétimo dia.

Esses capítulos representam os dias em que José ficou acamado no hospital antes de sua morte. Destes, passa seis dias fingindo estar em coma, acompanhando as conversas, as disputas e brigas dos filhos pela herança, pela conta do hospital, por questões quaisquer, com agressões verbais gratuitas, reclamações e ingratidão ao trabalho realizado por ele. O filho caçula é o único que efetivamente se importa com a situação do pai: 


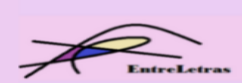

REVISTA ENTRELETRAS (ARAGUAÍNA), V. 12, N. 3, SET./DEZ. 2021 (ISSN 2179-3948 - ONLINE)

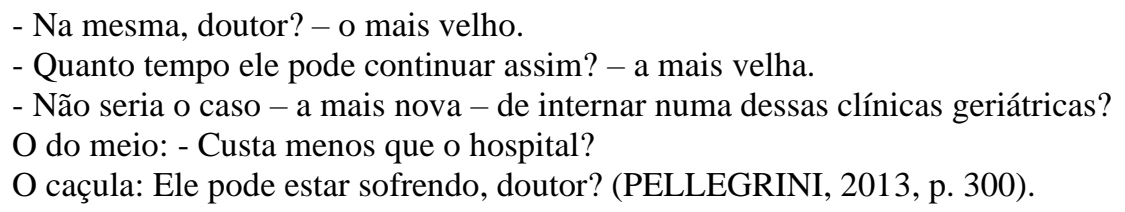

No quinto dia é levado ao CTI (Centro de tratamento intensivo), de onde, ao ficar sozinho, tenta e consegue escapar. É encontrado ao lado de fora do hospital por uma repórter, que ali noticiava a greve dos funcionários da Santa Casa. Semi delirando, o idoso quer retornar à sua Londrina, à terra-vermelha:

\footnotetext{
- Não essa Londrina, eu quero ir pra terra-vermelha.

E continua a se arrastar para fora, lá onde se vê uma ou outra planta de jardim, dessas plantas pisadas e escarradas pelo povo, as folhas rasgadas, enfumaçadas de cigarro, mas são plantas e estão ou devem estar plantadas na terra, e para lá ele vai se arrastando. [...]

Fecha os olhos.

- Eu só queria morrer do jeito que procurei viver - abre os olhos - Em paz.

Fecha os olhos e não abre mais. (PELLEGRINI, 2013, p. 385).
}

As reflexões de um José ranzinza, desiludido com sua situação familiar - apesar da vida que levou e do quanto prosperou social e financeiramente -, e com o destino de Londrina, é percebido desde as primeiras páginas da narrativa. Suas tentativas de preservar a mata são todas em vão, seu primogênito, que se tornou agricultor, não respeitou a propriedade: “- Terra é pra plantar, sô! Lavoura não dá debaixo de árvore nem boi come sombra!” (PELLEGRINI, 2013, p. 363).

Ao término de sua vida, a vingança de José foi doar o que restara de sua herança, o Hotel Pioneiro e sua casa, ao município para a instalação de uma escola de artes e ofícios, e seus investimentos em ações destinadas à manutenção da escola, à pesquisa e preservação da mata e da fauna local. Com exceção do filho caçula, a família fica revoltada com o testamento, a qual, após tentativas de corromper o advogado, descobrem a parte que lhes cabe:

\footnotetext{
O advogado diz que não, os cinco por cento restantes ficam para os filhos, um por cento para cada um.

- Agora, se me dão licença, está quase na hora do enterro.

O advogado sai, o portão range de novo, o caçula sorri lembrando do que dizia o pai:

- Amigo meu tem que ser madeira-de-lei - pega a faca de prata - E parente a gente tem, amigo a gente escolhe... (PELLEGRINI, 2013, p. 392).
}

Essa é a última crítica que José deixa para a terra vermelha, onde alguns dirão que era louco, outros que era um homem de coragem, fazendo-nos refletir que, conforme Fleck (2007, p. 146), “olhares oblíquos sobre um passado comum podem resultar em futuras esperanças 


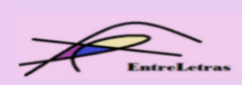

REVISTA ENTRELETRAS (ARAGUAÍNA), V. 12, N. 3, SET./DEZ. 2021 (ISSN 2179-3948 - ONLINE)

compartilhadas de um tempo melhor para todos". Indiretamente, esse foi o pedido do protagonista, um apelo a um futuro diferente, para então “[...] depois das águas e do fogo, e depois das terras e das guerras e dos ventos, enfim descansa[r], como se diz e até há quem acredite, descansa na Terra Vermelha.” (PELLEGRINI, 2013, p. 394).

\section{Considerações finais}

Nos interstícios da historiografia tradicional, as narrativas híbridas de história e ficção contemporâneas realizam uma releitura crítica do passado. A partir da produção paranaense, o presente artigo confirma a capacidade das narrativas híbridas de história e ficção em ressignificar a história do estado, possibilitando uma perspectiva distinta àquela propagada pelo discurso histórico convencional.

Ao realizar a análise de Terra vermelha (2013), de Domingos Pellegrini, verificamos como, por meio de estratégias próprias da modalidade mediadora do gênero, a diegese realiza uma atualização do processo de colonização e imigração no norte do Paraná de modo crítico e problematizador. Ao mesmo tempo, proporciona um diálogo questionador da historiografia nacional e reflexões sobre as confluências e entrelaçamentos entre o passado e presente.

Os estudos dos romances históricos paranaenses, portanto, permitem-nos reavaliar as concepções perpetuadas sobre o processo de colonização do estado, bem como seus fluxos migratórios e seu desenvolvimento urbano, comumente avaliados de forma apologética pela historiografia oficializada.

Desse modo, Terra Vermelha (2013), bem como os títulos com os quais dialoga, configuram-se como instrumentos à prática de interrogar-nos sobre o discurso histórico paranaense, e contribuem, assim, para uma percepção mais crítica, revisionista e descolonizadora da história tradicional, além de fornecerem traços e elementos para a melhor compreensão e conscientização sobre a nossa história cultural.

\section{Referências}

BENJAMIN, Walter. O narrador. In: BENJAMIN, Walter. Magia e técnica, arte e política: ensaios sobre literatura e história da cultura. Tradução de Sérgio Paulo Rouanet. 8. ed. revista - São Paulo: Brasiliense, 2012 - (Obras Escolhidas v. 1) p. 213-240.

FLECK, Gilmei Francisco. As aventuras do descobrimento da América em El último crímen de Colón (2001), de M. L. Levinas. In: CARLOS, Ana Maria; ESTEVES, Antonio R. (Orgs.) 


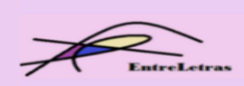

REVISTA ENTRELETRAS (ARAGUAÍNA), V. 12, N. 3, SET./DEZ. 2021 (ISSN 2179-3948 - ONLINE)

Ficção e história: leituras de romances contemporâneos. Assis: FCL - Assis - UNESP Publicações, 2007. p. 131-148.

FLECK, Gilmei Francisco. O romance histórico contemporâneo de mediação: entre a tradição e o desconstrucionismo - releituras críticas da história pela ficção. Curitiba: CRV, 2017.

LÓPEZ BADANO, Cecilia. La novela histórica latinoamericana entre dos siglos. Un caso: Santa Evita, cadáver exquisito de paseo por el canon. Madrid: Consejo Superior de Investigaciones Científicas, 2010.

MARCONDES, Sandra. Brasil, amor à primeira vista!: viagem ambiental no Brasil do século XVI ao XXI. São Paulo: Petrópolis, 2005.

MATA INDURÁIN, Carlos. Retrospectiva sobre la evolución de la novela histórica. In: SPANG, K.; ARELLANO, I.; MATA-INDURÁIN, C. (Ed.). La novela histórica: teoría y comentarios. Barañáin: EUNSA, 1995. p. 13-63.

MENDONÇA, Joseli Maria Nunes. Revisitando a história da imigração e da colonização no Paraná provincial. Antíteses, V. 8, N. 16, jul./dez. 2015, p. 204-226

NASCIMENTO, Naira de Almeida. Uma leitura da terra e do mar em Domingos Pellegrini e Miguel Sanches Neto. Estudos de Literatura Brasileira Contemporânea. N. 33, Brasília, jan./jun. 2009, pp. 141-155.

PEGORARO, Ivo. Quatro gerações. Francisco Beltrão: Jornal de Beltrão, 2018.

PELLEGRINI, Domingos. Terra vermelha. São Paulo: Leya, 2013.

PRIORI, Angelo, et al. História do Paraná: séculos XIX e XX. Maringá: Eduem, 2012.

RIBEIRO, Alessandra Pilati. As relações entre ficção histórica, memória e autobiografia na obra Terra vermelha de Domingos Pellegrini. 2017. 93 f. Dissertação (Mestrado em Teoria Literária) - Centro Universitário Campos de Andrade - UNIANDRADE. Curitiba, 2017.

SANCHES NETO, Miguel. A verdade nos falsos romances históricos. Valor Econômico. Ponta Grossa, 2013. Disponível em: https://valor.globo.com/eu-e/noticia/2013/07/05/a-verdade-nosfalsos-romances-historicos.ghtml Acesso em 28/09/2021.

SHARPE, Jim. A história vista de baixo. In: BURKE, Peter (Org.). A escrita da história: novas perspectivas. Trad. de Magda Lopes. São Paulo: Editora Unesp, 1992. p. 39-62.

Recebido em 08 de novembro de 2021. Aceito em 03 de janeiro de 2022. 